\title{
Uitwinning van zekerheidsrechten in vrijheid
}

\author{
Prof. mr. J.J. van Hees*
}

'Und das Gesetz nur kann uns Freiheit geben.'

\section{Inleiding}

Het verlenen van krediet is mooi, want nuttig voor het bevorderen van het handelsverkeer, en kan lucratief zijn. Risicovol is het echter ook, om zomaar geld uit te lenen. Wanneer een schuldenaar in gebreke blijft met de betaling van zijn schuld, valt het voor een kredietgever niet mee om betaling af te dwingen. Weliswaar mag hij zijn vordering op het vermogen van zijn schuldenaar verhalen, maar de weg daarnaartoe is vaak moeizaam en met tegenvallend resultaat. Allereerst zal hij moeten beschikken over een executoriale titel. In theorie heeft hij die als de vordering is vastgelegd in een authentieke akte, maar dat komt in de praktijk niet veel voor. Dat betekent dan een - kostbare en tijdrovende - gang naar de rechter om een vonnis te verkrijgen. In ieder geval zal hij onderzoek moeten doen naar vermogensbestanddelen van de schuldenaar die zich voor verhaal lenen en daar, als hij verstandig is, beslag op leggen. Anders bestaat het risico dat de goederen uit het vermogen van de schuldenaar zijn verdwenen, of door hem zijn bezwaard met rechten van derden, tegen de tijd dat hij gereed is om tot executie over te gaan. Het helpt ook niet echt dat de wet voorschrijft dat de beslagen goederen door middel van een openbare verkoop te gelde moeten worden gemaakt. Dit is lang niet altijd de juiste methode om een maximale opbrengst te verkrijgen.

Last but not least komt een onheil zelden alleen. Wanneer de schuldenaar zijn krediet niet aflost, zal hij vermoedelijk ook andere schuldeisers onbetaald laten en die zullen zich eveneens op zijn goederen willen verhalen. De opbrengst zal in dat geval pari passu met deze schuldeisers moeten worden gedeeld. Met een beetje pech wordt de schuldenaar ook nog failliet verklaard, wat betekent dat de curator de executie overneemt en de opbrengst met alle andere schuldeisers zal moeten worden gedeeld. De praktijk van de faillissementsafwikkeling wijst uit dat de gewone (concurrente) schuldeisers in dat geval betaling

Prof. mr. J.J. van Hees is advocaat bij RESOR en als hoogleraar Financiering, Zekerheden en Insolventie verbonden aan het Onderzoekcentrum Onderneming \& Recht van de Radboud Universiteit Nijmegen.

1. J.W. von Goethe, Natur und Kunst, 1802. van hooguit enkele procenten van hun vordering tegemoet kunnen zien. ${ }^{2}$

Deze bezwaren spelen niet, althans in mindere mate, als de kredietgever voor zijn vordering zekerheid heeft bedongen in de vorm van een pand- of hypotheekrecht. Pand- en hypotheekhouders hebben het recht van parate executie. $\mathrm{Zij}$ mogen executeren zodra de schuldenaar in verzuim is met zijn verplichtingen. Beslag leggen is niet nodig, want het goederenrechtelijke karakter van hun zekerheid brengt met zich dat een vervreemding of bezwaring van de goederen waarop hun zekerheidsrecht rust niet aan verhaal in de weg staat. Bovendien biedt de wet mogelijkheden om de goederen op een andere manier dan door openbare verkoop te gelde te maken. Andere schuldeisers vormen daarbij nauwelijks een bedreiging. Aan een vordering die gedekt is door een pand- of hypotheekrecht is een hoge rang verbonden, zodat de vordering - een enkele uitzondering daargelaten - als eerste uit de opbrengst dient te worden voldaan. Ook een faillissement van de schuldenaar hoeft geen roet in het eten te gooien, omdat de Faillissementswet bepaalt dat pand- en hypotheekhouders hun rechten ook tijdens het faillissement kunnen uitoefenen.

Geen wonder dus dat kredietverschaffers in de regel zekerheden in de vorm van pand- of hypotheekrechten verlangen van de schuldenaar. Toch is het voor de pand- en hypotheekhouder niet alleen maar vrijheid (en blijheid) wat de klok slaat. Ook de uitwinning van deze zekerheidsrechten blijkt in de praktijk een aanmerkelijk moeizamer en complexer traject dan uit voorstaande weergave lijkt.

Een bijdrage als deze leent zich niet voor een bespreking van alle perikelen die zich bij de executie van pand- en hypotheekrechten kunnen voordoen. Ik licht er een tweetal uit dat zich in de praktijk met een zekere regelmaat manifesteert. Zij doen zich voor bij de uitwinning van pand en hypotheek in het faillissement van de schuldenaar.

Allereerst zet ik de hoofdlijnen uiteen van de regels die gelden voor de uitwinning van pand- en hypotheekrechten, zowel in

2. Aldus valt af te leiden uit het CBS-rapport 'Faillissementen: oorzaken en schulden 2015', waarover J.J. van Hees, Het faillissement als achterhaald concept, in: S.E. Bartels e.a. (red.), Vertrouwen in het burgerlijke recht. Liber amicorum S.C.J.J. Kortmann (Onderneming en Recht, deel 100), Deventer: Wolters Kluwer 2017, p. 187 e.v. 
als buiten het faillissement van de zekerheidsverschaffer. Vervolgens ga ik in op de beide hiervoor bedoelde bijzondere kwesties. De eerste betreft het probleem van toerekening van de opbrengst van de verkoop van een onderneming aan daartoe behorende verpande en verhypothekeerde goederen. Daarna bespreek ik de beperkingen die voor de zekerheidsgerechtigde kunnen voortvloeien uit de in art. 58 lid $1 \mathrm{Fw}$ geregelde bevoegdheid van de curator om aan de uitwinning een termijn te stellen. Aan de hand van het voorgaande rond ik af met enkele bespiegelingen over de vraag hoe aan deze kwesties tegemoet zou kunnen worden gekomen.

\section{Uitwinning}

\subsection{Algemeen}

Uitgangspunt van ons executierecht is nog steeds dat uit te winnen goederen in het openbaar worden verkocht. ${ }^{3}$ Voor uitwinning door middel van executoriaal beslag vormt dit uitgangspunt zelfs een absolute regel. Een uitzondering geldt daar slechts voor executie van vorderingen (derdenbeslag). Vorderingen kunnen ook worden uitgewonnen door inning, waarbij de derde-beslagene hetgeen hij verschuldigd is aan de beslagene afdraagt aan de deurwaarder. ${ }^{4}$

Ook bij de executie van een pand- of hypotheekrecht stelt de wet de openbare verkoop van de bezwaarde goederen voorop. ${ }^{5}$ In afwijking van deze hoofdregel biedt de wet de pand- en hypotheekhouder echter nog andere mogelijkheden om deze te gelde te maken. Verpande vorderingen kunnen, net als bij executoriaal beslag, door de pandhouder worden geïncasseerd. Daarnaast biedt de wet zowel de pandhouder als de hypotheekhouder de mogelijkheid tot onderhandse verkoop. ${ }^{6}$ Voor de hypotheekhouder houdt het daarmee in principe op, alhoewel - zoals hierna nog zal worden besproken - een faillissement van de hypotheekgever ruimte kan geven aan andere vormen van uitwinning. ${ }^{7}$ De pandhouder is echter - ook buiten faillissement - beter bedeeld. Zo kan de voorzieningenrechter op verzoek van de pandhouder of de pandgever bepalen dat het verpande goed op een andere wijze dan in het openbaar kan worden verkocht. Ook kan de pandhouder de voorzieningenrechter verzoeken een bedrag te bepalen waarvoor het goed aan hem zal 'verblijven', dat wil zeggen dat de pandhouder

3. Asser Procesrecht/Steneker $52019 / 8$.

4. Art. 477 Rv. Sinds de aanpassing van art. 3:268 lid 2 BW per 1 januari 2015 kan ook de executoriaal beslaglegger een verzoek tot onderhandse verkoop van een (verhypothekeerd) registergoed doen.

5. Art. 3:250 lid 1 resp. art. 3:268 lid 2 BW.

6. Art. 3:251 resp. art. 3:268 lid 2 BW.

7. In de literatuur wordt overigens wel angedrongen op gelijkstelling van de mogelijkheden voor een afwijkende wijze van executie door de hypotheekhouder met die van de pandhouder. Zie N.E.D. Faber \& N.S.G.J. Vermunt, Afwijkende wijzen van executie bij pand en hypotheek; uitwinning in het digitale tijdperk, in: C.J.H. Jansen, B.A. Schuijling \& I.V. Aronstein (red.), Onderneming en digitalisering (Onderneming en Recht, deel 116), Deventer: Wolters Kluwer 2019, p. 160-161 met verdere verwijzingen. zich het goed kan toe-eigenen. ${ }^{8}$ Belangrijker nog is wellicht de mogelijkheid dat de pandhouder en de pandgever, nadat de pandhouder bevoegd is geworden om te executeren, ${ }^{9}$ een afwijkende wijze van verkoop kunnen overeenkomen zonder dat tussenkomst van de voorzieningenrechter is vereist.

Statistisch materiaal ontbreekt, maar de stelling lijkt gerechtvaardigd dat openbare verkoop door een pand- of hypotheekhouder in de praktijk eerder uitzondering dan regel is. Dat is ook niet verwonderlijk. Al bij de invoering in 1992 van de mogelijkheid voor de pand- en hypotheekhouder om onderhands te executeren werd door de wetgever onderkend dat openbare verkoop in veel gevallen niet de juiste weg is om een maximale opbrengst te genereren. ${ }^{10}$ Ook bij de recente aanpassingen van het executierecht gaat de wetgever ervan uit dat een onderhandse verkoop in het algemeen tot een hogere verkoopopbrengst leidt. ${ }^{11}$ Voor sommige goederen, zoals (niet-beursgenoteerde) aandelen of specifieke (ondernemingsgebonden) installaties en gebouwen, zal een openbare verkoop zelfs in het geheel niet geschikt zijn om een redelijke opbrengst te verkrijgen. $^{12}$

\subsection{Uitwinning tijdens faillissement}

Uitwinning door pand- of hypotheekhouders vindt vaak plaats tijdens het faillissement van de schuldenaar. Het ligt voor de hand dat een schuldenaar die niet in staat is zijn zekerheidsgerechtigde kredietverschaffers te voldoen al snel in aanmerking komt om failliet te worden verklaard, hetzij op eigen aangifte, hetzij op aanvraag van een van zijn schuldeisers. Bij een rechtspersoon kan de dreiging van bestuurdersaansprakelijkheid voor het aangaan van nieuwe verplichtingen bij voortzetting van de onderneming ${ }^{13}$ ook aanleiding zijn om aangifte tot faillietverklaring te doen.

Als de failliete schuldenaar een onderneming drijft die nog levensvatbaar is, ligt een openbare verkoop van de goederen van de schuldenaar niet voor de hand. Een verkoop van de onderneming, of van levensvatbare onderdelen daarvan, zal in het algemeen een (veel) hogere opbrengst opleveren dan verkoop van de afzonderlijke goederen die tot de boedel behoren. Door de goederen als onderdeel van de onderneming (mee) te

8. Art. 3:251 lid 1 BW. Zie daarover A. Steneker, Pandrecht (Mon. BW nr. B12a), Deventer: Kluwer 2012, nr. 43 en Faber \& Vermunt 2019, p. 154 e.v.

9. Dat is het moment waarop het verzuim van de schuldenaar van de verzekerde vordering intreedt (art. 3:248 lid 1 BW).

10. MvA II, Parl. Gesch. BW Boek 3, p. 824; Parl. Gesch. BW Inv. 3, 5 en 6, wijziging Rv, Wet RO en Fw 1992, p. 196-197.

11. Zie de MvT bij de wet van 1 oktober 2014 tot wijziging van het Wetboek van Burgerlijke Rechtsvordering en het Burgerlijk Wetboek in verband met het transparanter en voor een breder publiek toegankelijk maken van de executoriale verkoop van onroerende zaken, Kamerstukken II 2012/13, 33484, nr. 3, p. 2-3. Op p. 3 refereert de minister aan onderzoek door het WODC waaruit blijkt dat de opbrengst van een onroerende zak bij een veiling gemiddeld 30\% lager ligt dan de opbrengst die een onderhandse verkoop zou hebben opgeleverd.

12. Zie ook Faber \& Vermunt 2019, p. 152 e.v.

13. HR 6 oktober 1989, ECLI:NL:HR:1989:AB9521, NJ 1990/286 (Beklamel). 
verkopen kan de daarin besloten goodwill te gelde worden gemaakt. De curator kan een optimaal, op de aard van de te verkopen onderneming afgestemd, verkoopproces inrichten, dat uiteindelijk moet resulteren in een (door de rechter-commissaris goed te keuren) koopovereenkomst met de hoogstbiedende gegadigde. ${ }^{14}$

Voor pand- en hypotheekhouders kan een dergelijke verkoop door de curator voordelig zijn. Weliswaar kunnen zij in beginsel zelf de tot zekerheid strekkende goederen verkopen. Panden hypotheekhouders zijn immers separatisten en kunnen hun rechten uitoefenen 'alsof er geen faillissement was'. ${ }^{15}$ Daar staat tegenover dat zij veelal niet zelfstandig de onderneming als geheel te koop aan kunnen bieden om aldus de daarin besloten meerwaarde ten opzichte van de optelsom van de opbrengsten van de afzonderlijke goederen te realiseren. ${ }^{16}$ Dat geldt zelfs als alle relevante goederen van de onderneming zijn verpand en verhypothekeerd. Zo zullen pand- en hypotheekhouders niet in staat zijn de administratie van de onderneming, waaronder niet alleen de boekhouding, maar ook klantenbestanden en dergelijke, aan een geïnteresseerde koper aan te bieden. Ook is het voor hen veel lastiger, anders dan voor de curator, om in het kader van een verkoop van de onderneming afspraken te maken over de overname van voor de onderneming noodzakelijk personeel en contracten met belangrijke leveranciers en afnemers.

Daar staat tegenover dat ook de curator afhankelijk is van de medewerking van de pand- en hypotheekhouders als hij de onderneming zou willen verkopen. Als gevolg van hun separatistenpositie kan hij de tot de onderneming behorende verpande en verhypothekeerde goederen in beginsel ${ }^{17}$ slechts verkopen onder handhaving van de daarop rustende zekerheidsrechten. Dat is vermoedelijk genoeg reden voor een gegadigde om van aankoop af te zien. In de praktijk zullen de curator en de zekerheidsgerechtigden dan ook trachten om tot overeenstemming te komen over verkoop van de onderneming door de curator.

Ook als er geen sprake is van een verkoop van een onderneming kan het voor de zekerheidsgerechtigden overigens aantrekkelijk zijn de uitwinning van de bezwaarde goederen aan de curator over te laten. De curator is vaak beter gepositioneerd om geschikte kopers voor de goederen te vinden of verpande vorderingen te innen en aldus de opbrengst te maxima-

14. Hij heeft deze bevoegdheid op grond van art. $176 \mathrm{Fw}$.

15. Art. 57 lid 1 Fw.

16. De wetgever heeft wel beoogd een dergelijke gezamenlijke verkoop van verpande en verhypothekeerde zaken in bepaalde gevallen te faciliteren (art. 3:254 BW). Zie daarover Asser/Van Mierlo 3-VI 2016/388 en J.J. van Hees, Het einde van de hulpzaak, het probleem van de hypotheekhouder, in: W.C.L. van der Grinten, S.C.J.J. Kortmann, A.J.M. Nuytinck \& H. Wammes (red.), Onderneming en nieuw burgerlijk recht, Zwolle: W.E.J. Tjeenk Willink 1991, p. 209 e.v.

17. Dat is anders wanneer de curator aan de pand- en/of hypotheekhouder op de voet van art. $58 \mathrm{Fw}$ een redelijke termijn heeft gesteld om tot verkoop over te gaan en deze verkoop niet binnen deze termijn is gerealiseerd. Ik kom daar hierna op terug. liseren. Hij heeft toegang tot de administratie en kan de medewerking van (het bestuur van) de schuldenaar verlangen. ${ }^{18}$ Bovendien heeft hij, zoals opgemerkt, de vrijheid om het verkoopproces optimaal in te richten afhankelijk van de aard van de goederen.

In alle gevallen waarin de curator in overleg met de pand- of hypotheekhouder de bezwaarde goederen verkoopt, heeft dit te gelden als een executie van het zekerheidsrecht met de daaraan verbonden gevolgen. ${ }^{19}$ Dat betekent onder meer dat de opbrengst buiten de boedel om wordt afgewikkeld en dus niet in de omslag van de algemene faillissementskosten wordt betrokken. ${ }^{20}$ Voor zijn werkzaamheden in het kader van de uitwinning ten behoeve van de zekerheidsgerechtigden zal de curator wel een vergoeding verlangen, de zogenaamde boedelbijdrage. Voor deze vergoeding zijn weliswaar richtlijnen gepubliceerd, ${ }^{21}$ maar de praktijk leert dat deze richtlijnen niet zonder meer plegen te worden gevolgd en de uiteindelijke vergoeding een onderhandelingsresultaat is. ${ }^{22}$

\section{Toerekening en goodwill}

Bij een verkoop van de onderneming van de gefailleerde schuldenaar door de curator speelt niet alleen de vraag naar een (redelijke) vergoeding voor diens werkzaamheden. Ook de toerekening van de gerealiseerde opbrengst van de met de onderneming meeverkochte goederen, en in het bijzonder de daaraan toe te rekenen goodwill, blijkt in een dergelijk geval nogal eens onderwerp van debat te zijn. Dat de zekerheidsgerechtigde aanspraak kan maken op de meerwaarde die wordt gerealiseerd doordat de goederen waarop zijn zekerheidsrecht rust als onderdeel van een onderneming worden verkocht, is niet voor betwisting vatbaar. ${ }^{23}$ De verkoop door de curator is immers aan te merken als executie van het zekerheidsrecht. De (meer)opbrengst die als gevolg van de keuze van de zekerheidsgerechtigde voor deze wijze van executeren is gerealiseerd, komt aan hem toe, ook al zou de opbrengst lager zijn geweest als hij de goederen op een andere manier had uitgewonnen. Het probleem zit hem vaak in de bepaling van deze meeropbrengst. Een koper die een bod doet op een onderneming pleegt dit bod nu eenmaal niet, of hooguit in beperkte mate, uit te splitsen naar de verschillende onderdelen van deze onderneming. Dat betekent dat de toerekening van de koopprijs aan de samenstellende elementen van de onderneming

18. Zie art. 105 e.v. Fw.

19. HR 25 februari 2011, ECLI:NL:HR:2011:BO7109, JOR 2014/271, NJ 2012/74 (ING/Hielkema q.q.); HR 15 maart 2013, ECLI:NL:HR: 2013:BZ4072, JOR 2014/270 (Staatssecretaris van Financiën/X); zie ook N.E.D. Faber \& N.S.G.J. Vermunt, Eigenlijke (wettelijke) en oneigenlijke (contractuele) lossing, MvV 2015, afl. 7-8, p. 235 e.v.

20. Art. 182 jo. art. 57 lid $1 \mathrm{Fw}$.

21. De zogenaamde Separatistenregeling, bijlage bij de 'Recofa-richtlijnen voor faillissementen en surseances van betaling', opgesteld door het landelijk overlegorgaan van rechters-commissarissen in faillissementen en surseances van betaling (Recofa) en te vinden op www.rechtspraak.nl.

22. Zie daarover ook de forumbijdrage van Ph.W. Schreurs, Naar een herverdeling, TvI 2020/14.

23. Anders: J.L. van den Heuvel \& L.J. van Eeghen, Lossing door de curator, TvI 2019/25 en hun naschrift in TvI 2019/43 bij de reactie van K.A. Messelink \& M.L. Tuil in TvI 2019/42. 


\section{Maandblad Vermogensrecht}

door de betrokkenen aan verkoperszijde, de curator en de zekerheidsgerechtigde(n), zal moeten worden vastgesteld. De belangen lopen daar niet parallel. De curator heeft immers belang bij een zo hoog mogelijke toerekening aan de onderdelen die niet bezwaard (kunnen) zijn met zekerheidsrechten, zodat een groter deel van de opbrengst ter vrije beschikking komt in de boedel. De zekerheidsgerechtigden op hun beurt hebben er uiteraard belang bij zo veel mogelijk van de opbrengst toe te rekenen aan hun onderpand.

Dit soort waarderingsvraagstukken zijn niet ongewoon. Zij kunnen zich ook voordoen buiten het kader van toerekening van opbrengsten aan met zekerheidsrechten bezwaarde goederen. Zo zal het bij de verkoop van een onderneming die in concernverband wordt gedreven niet altijd eenvoudig zijn de koopprijs toe te rekenen aan de (boedels van de) verschillende betrokken groepsmaatschappijen. In alle gevallen geldt dat het verstandig is dit punt vóór de verkoop van de onderneming onder ogen te zien en daarover afspraken te maken. ${ }^{24}$

\section{Art. 58 Fw: de redelijke termijnstelling}

Een pand- of hypotheekhouder zal niet altijd de uitwinning aan de curator willen overlaten. Als de betrokkenheid van de curator in zijn ogen geen toegevoegde waarde heeft, kan hij gebruik maken van zijn bevoegdheid als separatist en zijn rechten uitoefenen alsof er geen faillissement was. ${ }^{25} \mathrm{Hij}$ kan dan zelf, op een van de eerder beschreven manieren, de hem tot zekerheid strekkende goederen uitwinnen. Daarbij dreigt echter wel een gevaar. De curator heeft op grond van het eerste lid van art. $58 \mathrm{Fw}$ de bevoegdheid om pand- en hypotheekhouders een redelijke termijn te stellen waarbinnen deze hun rechten moeten hebben uitgeoefend. Hebben zij 'het onderpand niet binnen deze termijn verkocht', dan kan de curator de goederen opeisen en deze zelf verkopen. ${ }^{26}$ Weliswaar behoudt de separatist zijn aanspraak op de opbrengst, maar daarover worden dan wel eerst de algemene faillissementskosten omgeslagen. ${ }^{27}$

Deze bevoegdheid van de curator heeft in de afgelopen decennia een heftige dynamiek gekend. ${ }^{28}$ Daar is een aantal oorzaken voor aan te wijzen. De belangrijkste is waarschijnlijk dat curatoren, mede als gevolg van de jurisprudentie van de Hoge Raad, in toenemende mate met negatieve boedels te maken hebben gekregen. Het stellen van een termijn creëert

24. Deze afspraken kunnen zich ook beperken tot een (snelle en eenvoudige) wijze van beslechting van geschillen indien die zich bij de verdeling van de opbrengst zouden voordoen.

25. Art. 57 lid $1 \mathrm{Fw}$.

26. In de literatuur wordt, mede n.a.v. het arrest HR 22 juni 2007, ECLI:NL:HR:2007:BA2511, NJ 2007/520 m.nt. PvS (ING/Verdonk q.q.), r.o. 3.4, algemeen aangenomen dat art. 58 lid 1 Fw ook ziet op de inning van verpande vorderingen door de pandhouder; zie GS Faillissementswet, art. $58 \mathrm{Fw}$, aant. 2.8.1.

27. Zie art. $182 \mathrm{Fw}$.

28. Voor uitvoerige beschouwingen daarover verwijs ik naar TvI 2016, afl. 5, een themanummer gewijd aan de bepaling van art. 58 lid $1 \mathrm{Fw}$, met bijdragen van M. van Wingerden (TvI 2016/27), F.M.J. Verstijlen (TvI 2016/28) en R.J. van Galen (TvI 2016/29). de mogelijkheid dat, als de pand- of hypotheekhouder de uitwinning niet tijdig weet te realiseren en geen verlenging van de termijn verzoekt of verkrijgt, ${ }^{29}$ de opbrengst van de goederen kan worden aangewend ter dekking van de algemene faillissementskosten. Bij een negatieve boedel kunnen uit deze opbrengst dan de boedelschuldeisers, onder wie de curator met zijn salarisvordering, worden voldaan. Met de toename van het aantal negatieve boedels is de prikkel voor de curator vergroot om het middel van de termijnstelling in te zetten in een poging (nog enig) boedelactief te genereren. ${ }^{30}$

De Hoge Raad heeft met het Zalco I-arrest ${ }^{31}$ ook een steentje aan de commotie over deze bevoegdheid van de curator bijgedragen. In dit arrest oordeelde hij dat de rechter-commissaris niet verplicht is tot verlenging van de termijn, wanneer de uitoefening van het pand- of hypotheekrecht binnen de door de curator gestelde termijn (in redelijkheid) niet mogelijk blijkt of de pand- of hypotheekhouder van het niet-tijdig uitoefenen van zijn recht anderszins geen verwijt kan worden gemaakt. Ook in een dergelijk geval dient hij het belang van de pand- of hypotheekhouder bij verlenging van die termijn af te wegen tegen het belang van een voortvarende afwikkeling van de boedel en kan hij op die grond het verzoek afwijzen. Het feit dat de Hoge Raad in latere arresten duidelijk heeft gemaakt dat de curator van zijn bevoegdheden op grond van art. 58 lid $1 \mathrm{Fw}$ ook misbruik kan maken in de zin van art. 3:13 $\mathrm{BW},{ }^{32}$ heeft de pijn amper verzacht.

Van misbruik door de curator van zijn bevoegdheid tot termijnstelling zal overigens niet snel sprake zijn. Dat volgt al uit het feit dat art. 58 lid $1 \mathrm{Fw}$ voorschrijft dat de gestelde termijn 'redelijk' dient te zijn. Of een termijn redelijk moet worden geacht, is afhankelijk van alle relevante omstandigheden op het moment van de termijnstelling, waaronder de inschatting of de zekerheidsgerechtigde in staat moet worden geacht het onderpand tegen een aanvaardbare opbrengst te verkopen. ${ }^{33}$ Is er geen sprake van een redelijke termijn, dan blijft de termijnstelling zonder gevolg en kan de curator aan het verstrijken daarvan geen rechten ontlenen. ${ }^{34}$

Het feit dat de curator de termijn mede of uitsluitend stelt met het oog op de mogelijkheid om het onderpand na het

29. Volgens de bepaling van art. $58 \mathrm{Fw}$ is de rechter-commissaris bevoegd de termijn te verlengen, maar het ligt voor de hand dat de curator dit ook zelf kan doen.

30. Zie daarover ook Verstijlen 2016, p. 182.

31. HR 20 december 2013, ECLI:NL:HR:2013:2051, JOR 2014/86, NJ 2014/151.

32. HR 16 januari 2015, ECLI:NL:HR:2015:87, JOR 2015/308, NJ 2015/58 (T./Van der Molen q.q.) en HR 6 februari 2015, ECLI:NL:HR:2015:228, JOR 2015/309, NJ 2015/294 (Welage q.q./ Rabo). Zie daarover ook E.J.H. Schrage, Misbruik van bevoegdheid (Mon. BW nr. A4), Deventer: Wolters Kluwer 2019, p. 67-68.

33. T.T. van Zanten \& F.J.L. Kaptein, Rechtsuitoefening in de zin van art. 58 lid 1 Fw: wat moet de separatist allemaal binnen de termijn doen?, TvI 2013/10. Zie ook de noot van N.E.D. Faber in zijn JOR-annotaties van T./Van der Molen q.q. en Welage q.q./Rabo, sub 2.b.

34. Zie ook de noot van N.E.D. Faber in zijn annotaties onder T./Van der Molen q.q. en Welage q.q./Rabo, JOR 2015/309, sub 2.b. 


\section{Maandblad \\ Vermogensrecht}

ongebruikt verstrijken daarvan zelf te verkopen en aldus dekking te verkrijgen voor de algemene faillissementskosten, is in dit verband niet relevant. Het gegeven dat de termijn redelijk dient te zijn, gevoegd bij de taak van de curator om de boedel te vereffenen, ${ }^{35}$ rechtvaardigt op zichzelf de termijnstelling en is in overeenstemming met het doel van art. 58 lid 1 Fw: een voortvarende afwikkeling van de boedel. Daarmee is niet gezegd dat er onder omstandigheden geen sprake kan zijn van misbruik van bevoegdheid door de curator door op deze wijze de uitwinning van het onderpand te initiëren of zijn bevoegdheid tot opeising uit te oefenen. Indien daardoor de belangen van de zekerheidsgerechtigde of betrokken derden onevenredig worden geschaad ten opzichte van het belang van de boedel, zal de curator, zoals blijkt uit de hiervoor genoemde jurisprudentie, deze bevoegdheden niet kunnen inroepen. Anders dan in de literatuur wel wordt verdedigd, ${ }^{36}$ kan in deze afweging - naast het belang van een voortvarende afwikkeling van de boedel - ook het belang van de boedel worden betrokken om middelen te verkrijgen ter voldoening van de algemene faillissementskosten. ${ }^{37}$

\section{Enkele bespiegelingen}

Het vorenstaande schetst een beeld van de uitwinningsmogelijkheden van pand- en hypotheekhouders. De verschillen met een schuldeiser zonder een dergelijk zekerheidsrecht zijn groot. Door het recht van parate executie hoeft de pand- of hypotheekhouder niet eerst een moeizaam traject door voordat hij tot uitwinning kan overgaan. En bij de uitwinning zijn de mogelijkheden van de zekerheidsgerechtigde schuldeiser ruimer dan die van zijn concurrente collega. De laatste is in beginsel aangewezen op de openbare verkoop van goederen waar hij eerst nog beslag op moet leggen. Ten slotte mag de pand- of hypotheekhouder zich ook nog eens als eerste uit de opbrengst van het uitgewonnen goed voldoen.

De vrijheid van de pand- en hypotheekhouders, om in de termen van dit themanummer te blijven, is dan ook groot. Dat neemt niet weg dat ook zij bij hun uitwinningsactiviteiten belemmeringen ontmoeten. Twee daarvan zijn in deze bijdrage besproken. De eerste heeft betrekking op het feit dat bij een faillissement van de schuldenaar een verkoop van diens onderneming vaak de beste methode is om een maximale opbrengst voor het onderpand te realiseren. Daarvoor is echter overeenstemming met de curator vereist. Bovendien roept een dergelijke manier van uitwinning waarderingsvragen op, nu de koopprijs niet alleen de waarde van de ondergezette goederen representeert. Het oplossen van deze waarderingsvragen zal

35. Art. 68 lid 1 Fw. Tot de boedel behoren ook de goederen die met het zekerheidsrecht zijn bezwaard.

36. Zie o.m. Verstijlen 2016, p. 184

37. In het arrest T./Van der Molen q.q. was door de curator dit belang aangevoerd als reden voor zijn termijnstelling. Nu de Hoge Raad in cassatie als uitgangspunt nam dat de separatist binnen de termijn zou executeren en daaruit geen opbrengst voor de boedel viel te verwachten, achtte hij het oordeel van de rechtbank dat de curator daarmee een in redelijkheid te respecteren belang had bij de uitoefening van zijn bevoegdheden onbegrijpelijk. door onderhandeling moeten plaatsvinden, hetgeen in economische zin kosten oplevert en dus waarde verloren doet gaan.

De tweede belemmering die aan de orde is geweest en die in de praktijk een grote vlucht heeft genomen, houdt verband met de bevoegdheid die de wet de curator in faillissement geeft om de pand- of hypotheekhouder te dwingen binnen een redelijke termijn te executeren. De vrijheid van de separatist om voor de uitwinning zijn eigen tempo, en daarmee soms ook de wijze, van uitwinning te bepalen wordt hiermee sterk ingeperkt en daarmee ook zijn vrijheid om een tempo te kiezen om de executiewaarde te maximaliseren. Daarbij is van belang dat de meningen over de redelijkheid van een termijn kunnen verschillen en dat op voorhand, door de belangenafweging die dan moet plaatsvinden, moeilijk valt te voorspellen of een verzoek tot verlenging zal worden gehonoreerd. De gevolgen van een termijnoverschrijding zijn ernstig, aangezien de opbrengst van het onderpand in de omslag van de algemene faillissementskosten van de - veelal lege - boedel wordt betrokken.

De waarderingsvragen die bij de uitwinning van een onderneming spelen, zijn onder het huidige recht niet eenvoudig te elimineren. Ons vermogensrecht is nu eenmaal gebaseerd op het uitgangspunt dat slechts individuele, voor overdracht vatbare goederen met een zekerheidsrecht kunnen worden bezwaard en een onderneming behelst veel meer dan dat. Dat betekent wel dat het vermogensrecht in dit opzicht niet goed (meer) aansluit bij de economische werkelijkheid, waarin een onderneming wel als voorwerp van een transactie kan fungeren. Het is niet waarschijnlijk dat deze kloof tussen het vermogensrecht en de economische realiteit door de rechtspraak zal worden gedicht, overigens los van de vraag of dat wenselijk is. De Hoge Raad geeft in ieder geval blijk van een grote terughoudendheid bij de aanpassing van het vermogensrechtelijke begrippenkader aan economische percepties. ${ }^{38}$ Dat betekent dat de wetgever dit zou moeten regelen.

Hetzelfde geldt voor het tweede besproken punt, de controverse die in faillissement kan ontstaan tussen de pand- of hypotheekhouder en de curator over de vraag wie van beiden gerechtigd is het onderpand te gelde te maken. Dit geschilpunt heeft, zoals toegelicht, een grote lading gekregen door de toename van de gevallen waarin de faillissementsboedel negatief is. Dat laatste is een probleem dat oplossing behoeft, maar daaronder ligt een principiëlere vraag. Die vraag is welke partij in geval van een faillissement het beste geëquipeerd kan worden geacht de tot de boedel behorende goederen, waaronder ook de goederen waarop een zekerheidsrecht rust, te gelde te maken.

38. Zie HR 6 december 2019, ECLI:NL:HR:2019:1909, JOR 2020/74 (ING Bank/Thielen q.q.)., waarin de Hoge Raad oordeelde dat een assurantieportefeuille niet als een individuele zaak of vermogensrecht kan worden aangemerkt, ook al wordt een dergelijke portefeuille in het economisch verkeer als een eenheid beschouwd. Zie over dit arrest uitvoerig K.J. Krzemiński \& T.A. Hartman, De onverpandbaarheid van assurantieportefeuilles, MvV 2020, afl. 5, p. 179-187. 


\section{Maandblad} Vermogensrecht

Bij uitwinning van afzonderlijke goederen die geen onderdeel uitmaken van een (levensvatbare) onderneming zal dit in de regel niet zoveel uitmaken. Zowel de zekerheidsgerechtigde als de curator zal daartoe in staat zijn, al was het maar omdat de zekerheidsgerechtigde ook buiten het geval van faillissement deze klus zelf zal moeten klaren. De belangen zullen in zo'n situatie parallel lopen, omdat de separatist eveneens belang heeft bij een uitwinning die niet onnodig veel tijd kost en een zo hoog mogelijke opbrengst levert. Dat betekent dat er weinig aanleiding is voor een bijzondere bevoegdheid van de curator die hem in staat stelt de uitwinning door de separatist te initieren en eventueel naar zich toe te trekken. Op het moment dat er sprake van is dat de goederen worden gebruikt in het kader van een onderneming en als onderdeel daarvan dienen te worden verkocht, pleit er veel voor om de curator in dat geval het voortouw te geven. Ook daarvoor zal de wet echter moeten worden aangepast. ${ }^{39}$ Goethe had het twee eeuwen geleden al goed gezien.

39. Art. 3.6.9 van het Voorontwerp van de commissie-Kortmann uit 2007 belichaamde dit systeem. Zie daarover J.J. van Hees, De separatist apart genomen, Ondernemingsrecht 2008/134. 